\title{
Correlation between Cognitive Impairment and CSF Biomarkers in Amnesic MCI, non-Amnesic MCI, and Alzheimer's Disease
}

\author{
Andreas Haldenwanger ${ }^{\mathrm{a}}$, Paul Eling ${ }^{\mathrm{c}}$, Andreas Kastrup ${ }^{\mathrm{a}, \mathrm{d}}$ and Helmut Hildebrandt ${ }^{\mathrm{b}, \mathrm{d}, *}$ \\ ${ }^{a}$ Municipal Hospital of Bremen-Mitte, Department of Neurology, Stroke Unit, FRG, Bremen, Germany \\ ${ }^{\mathrm{b}}$ University of Oldenburg, Neuropsychology, FRG, Oldenburg, Germany \\ ${ }^{\mathrm{c}}$ Radboud University of Nijmegen, Donders Institute for Brain, Cognition and Behaviour, Nijmegen, The \\ Netherlands \\ ${ }^{\mathrm{d}}$ Municipal Hospital of Bremen-Ost, Department of Neurology, FRG, Bremen, Germany
}

Accepted 1 August 2010

\begin{abstract}
Decreased delayed recall, decreased amyloid- $\beta$ peptides $\left(\mathrm{A} \beta_{1-42}\right)$, and increased tau protein concentration in cerebrospinal fluid (CSF) are generally regarded to be valid neuropsychological and biological markers for Alzheimer's disease (AD). Previous studies failed to demonstrate clear-cut correlations between neuropsychological impairment and CSF markers. In this study we test recent models of disease progression, that propose that changes in CSF biomarkers already reach a plateau in a preclinical phase, before cognitive decline begins, that is, even before MCI can be diagnosed. We recruited 73 patients with probable $\mathrm{AD}(n=36)$ and mild cognitive impairment $(\mathrm{MCI})($ amnesic $\mathrm{MCI}=25$; non-amnesic $\mathrm{MCI}=12)$. We used the CERAD-NP, a widely used neuropsychological battery with norms for different age and education groups, and additional neuropsychological tests for assessing the cognitive profile of these patient groups. We found a significant correlation between $\mathrm{A} \beta_{1-42}$ in the CSF and memory performance for amnesic MCI patients, but not for non-amnesic MCI and AD patients. All other correlations between cognitive tasks and $\mathrm{A} \beta_{1-42}$ were not significant. Tau protein concentration in the CSF was not correlated with any neuropsychological marker in any of the patients groups. We conclude that the decrease of $\mathrm{A} \beta_{1-42}$ in the CSF mirrors disease progression during the early stages up into $\mathrm{AD}$ and therefore is not restricted to the preclinical phase. The decrease of $\mathrm{A} \beta_{1-42}$ reaches a plateau only in the full blown demented syndrome and further functional disease progression is then related to neurodegeneration without further reduction of $\mathrm{A} \beta_{1-42}$ in the CSF.
\end{abstract}

Keywords: $\mathrm{A} \beta_{1-42}$, Alzheimer's disease, cognitive speed, MCI, memory, total tau

\section{INTRODUCTION}

Cortical and limbic accumulation of intraneuronal neurofibrillary tangles (NFT) and extracellular amyloid plaques are the two main diagnostic neuropathological features of Alzheimer's disease (AD); other prominent changes include neuronal loss, synaptic loss, and glio-

\footnotetext{
${ }^{*}$ Correspondence to: Helmut Hildebrandt, Ph.D., Klinikum Bremen Ost, Department of Neurology, Züricher Str. 40, 28325 Bremen, Germany. Tel.: +49 421408 1599; Fax: +49 421408 2599; E-mail: helmut.hildebrandt@uni-oldenburg.de.
}

sis. According to the amyloid cascade hypothesis of Hardy and Selkoe, accumulation of amyloid- $\beta$ peptides $(\mathrm{A} \beta)$ in the brain as a result of genetic mutations in the $\mathrm{A} \beta \mathrm{PP}$ gene is the primary mechanism driving $\mathrm{AD}$ pathogenesis [1,2]. Progression of the disease, including formation of neurofibrillary tangles containing tau protein, has been proposed to result from an imbalance between $\mathrm{A} \beta$ production and $\mathrm{A} \beta$ clearance. The relevance of the amyloid hypothesis has been questioned for the much more frequent multifactorial sporadic form of $\mathrm{AD}$. In some studies, a correlation has been found between elevated levels of $\mathrm{A} \beta$ in the brain 
and cognitive decline [3], but the quantity of amyloid deposits does not seem to correlate well with the degree of cognitive impairment. Several studies have reported patients without overt symptoms of dementia, yet showing many amyloid deposits in the brain at autopsy [4]. Given the pathologic changes in the AD brain, including accumulation of neurofibrillary tangles and $\mathrm{A} \beta$, reduced levels of synaptophysin, and elevated levels of glial fibrillary acidic protein (GFAP), Ingelsson and colleagues compared neuropathological changes in the temporal association cortex of AD cases with varying disease duration, with those of control brains, in an attempt to define the time course of these changes [5]. The two main findings of this study were: 1) Accumulation of $\mathrm{A} \beta$ was markedly increased in $\mathrm{AD}$ brains, independent of disease duration; and 2) The duration of dementia correlated with the degree of tangle formation, gliosis, and synaptic loss, but not with any of the $\mathrm{A} \beta$ measures. Ingelsson et al. [5], and later Jack et al. [6], therefore postulated that the pathological changes in AD occur in a sequential, neuroanatomically defined pattern, affecting cortical, subcortical, and limbic regions.

According to this view, the beginning of $\mathrm{A} \beta$ production and plaque formation antedates the clinical course of AD for years, and accelerates in an early phase, during a preclinical state, in which clinical or neuropsychological changes are not yet demonstrable. $\mathrm{A} \beta$ deposition appears to be already at a ceiling level when patients progress into clinical mild cognitive impairment (MCI) and into the dementia syndrome proper. At this stage of the disease, NFT formation, increasing gliosis, and progressive neuronal loss are initiated and continues into the clinical state of the full blown dementia. Therefore, $\mathrm{A} \beta$ concentration already has reached a steady state before an affected patient shows even MCI and the concentration of tau has increased over $50 \%$, compared to the healthy status [6]. This would explain why the correlation between these CSF markers and neuropsychological test scores is low in that phase or even not demonstrable, because when cognitive deterioration starts, CSF markers have already reached a plateau.

As Jack et al. [6] correctly state, the earliest and core symptom of $\mathrm{AD}$ is an episodic memory deficit, which exacerbates during the preclinical period [7], and is accompanied by increasingly severe disturbances in language, attention, executive functions, and mood in later phases of the disease [8,9]. More specifically, AD is characterized by an impairment in delayed recall, and several studies have shown that this impairment is a sensitive and partly specific feature of patients converting from MCI to AD [10-13]. Patients with amnesic cognitive impairment are more likely to represent an early stage of $\mathrm{AD}$ than patients with non-amnesic cognitive impairment [14]. Therefore, the earliest phase of $\mathrm{AD}$ neuropsychological testing should be focused on learning tests and on recall of learned information after a delay or following interfering materials $[7,15$, 16]. But the few studies, that have been published up to now on the correlation between CSF markers and cognitive decline, often relied on cognitive tests that are rather insufficient for this purpose, like the Mini Mental Status Examination (MMSE) [17-20]. This instrument yields a composite score of cognitive impairment and is rather insensitive to mild impairment. This may be the reason why these studies found negative or mixed results. Ivanoiu \& Sindic [21], using an extended neuropsychological battery, reported that a low level of $\mathrm{A} \beta_{1-42}$ (but not of tau) predicts a conversion to AD. Stomrud and collaborators [17] showed that a low level of $\mathrm{A} \beta_{1-42}$ is correlated with a decline in the MMSE score three years later in healthy elderly subjects. We have also found that $\mathrm{A} \beta_{1-42}$ and not tau protein correlates with memory functions [22]. This would suggest that $\mathrm{A} \beta_{1-42}$ still declines in CSF during the clinical phase of amnesic MCI, which would be highly relevant for the early identification of AD patients.

From the models of Jack et al. [6] and Ingelson et al. [5], two predictions can be derived: 1) $\mathrm{A} \beta_{1-42}$ concentration in the CSF should correlate with memory performance, but not with other cognitive functions, in preclinical AD patients (i.e., patients still without cognitive impairments), while there is no such correlation in MCI and AD patients; and 2) Tau protein concentration should correlate with severity of dementia in the period when the disease progresses into the dementia syndrome, but not in the preclinical stage and in clinical MCI.

\section{MATERIALS AND METHODS}

\section{Patients}

We recruited 73 patients with a cognitive impairment, admitted to the neurological department of our hospital over the last years. They were investigated with respect to a diagnosis of cognitive disorder. $\mathrm{Pa}-$ tients with definite other causes for their cognitive impairment, like inflammation or acute stroke, were excluded from the analysis. See for demographic details 
Table 1

Demographic data, Mini Mental Status Examination (MMSE), Becks depression inventory (BDI), CSF marker

\begin{tabular}{|c|c|c|c|c|c|c|}
\hline & \multicolumn{2}{|c|}{$\mathrm{AD}$} & \multicolumn{2}{|c|}{ amn-MCI } & \multicolumn{2}{|c|}{ n-amn-MCI } \\
\hline $\mathrm{n}$ & \multicolumn{2}{|c|}{36} & \multicolumn{2}{|c|}{25} & \multicolumn{2}{|c|}{12} \\
\hline \multirow[t]{2}{*}{$\mathrm{f} / \mathrm{m}$} & \multicolumn{2}{|c|}{$23 / 13$} & \multicolumn{2}{|c|}{$9 / 16$} & \multicolumn{2}{|c|}{$5 / 7$} \\
\hline & Mean & SD & Mean & SD & Mean & SD \\
\hline Age (y) & 70.1 & 9.2 & 70.0 & 7.6 & 64.8 & 7.8 \\
\hline Education (y) & 12.9 & 3.5 & 13.1 & 2.8 & 12.3 & 1.9 \\
\hline BDI & 6.9 & 7.0 & 11.7 & 8.7 & 10.0 & 8.1 \\
\hline MMSE (raw values) & 17.5 & 5.7 & 25.9 & 1.7 & 27.0 & 2.0 \\
\hline Tau-protein (ng/l) & 665 & 469 & 415 & 299 & 285 & 143 \\
\hline $\mathrm{A} \beta_{1-42}(\mathrm{ng} / \mathrm{l})$ & 469 & 235 & 661 & 323 & 813 & 289 \\
\hline
\end{tabular}

Abbreviations: $\mathrm{AD}=$ Alzheimer's disease, amn-MCI = amnesic mild cognitive impairment, n-amn-MCI = non-amnesic mild cognitive impairment, BDI = Beck Depression Inventory, MMSE $=$ Mini Mental Status Examination, SD = Standard deviation.

Table 1. Recruitment was done as part of a prospective study on neuropsychological and biomarkers for differential diagnosis in dementia, which is still running and ultimately seeks to determine the significance of MRI based atrophy measurement and serum/CSF markers for explaining neuropsychological decline in these patient groups. The project was approved by the Ethics committee of the University of Oldenburg, and all subjects gave informed consent to participate in the project.

\section{Neuropsychological investigation}

All patients underwent a neuropsychological examination, including the German Version of the CERAD test battery [23-27], which is composed of the MMSE, a 15-item short version of the Boston Naming Test, semantic word fluency test for animals (one minute), word list learning (10 words, three trials), word list recall after distraction, word list recognition (10 target and 10 distractor words), figure copying and delayed figure recall. For additionally testing, we used the first-letter fluency test from the Leistungsprüfsystem 50+ test [28], which is a German version of the FAS test (generation of words starting with these letters for 1 minute), the Mehrfachwahl-Wortschatz-Intelligenztest [29], which was used as a measure for extent of and access to the vocabulary, the Zahlenverbindungstest of the Nürnburger Alters Inventar [30], which is similar to the Trail Making Test A, and the digit span forwards and backwards from the German version of the Wechsler Memory Scale [31], to investigate verbal working memory performance. The Beck Depression Inventory (BDI) [32] was used to assess mood and depression.

\section{Neurological investigation}

The neurological investigation included medical history, physical and neurological examination, laboratory blood sample testing, brain imaging, electroencephalography and a lumbar puncture for the determination of Tau protein and $\mathrm{A} \beta_{1-42}$ levels.

The blood sample analysis included blood count, erythrocyte sedimentation rate, electrolytes (sodium, potassium, chloride), creatine, urea, transaminases, blood glucose, TSH, C-reactive protein, vitamin B12, folic acid. Optional additional blood analyses included vitamins, TPPA, immunological parameter, HIV, copper metabolism, etc. An MRI or CT scan was performed for every patient to exclude other causes for cognitive impairment like stroke, tumor, or an inflammatory disease.

\section{Clinical diagnosis}

The clinical diagnosis of AD or MCI was based on best clinical judgment, based on the ICD 10 [33] and the guidelines of the German Neurological Society for diagnosing AD. The German guidelines are based on the criteria of the Diagnostic and Statistical Manual of Mental Disorders (DSM-IV) [34] and the National Institute of Neurological Disorders and Stroke-Alzheimer's Disease and Related Disorders (NINCDS-ADRDA) working group [35,36], but not fully identical with these (http://www.dgn.org/leitlinien-online.html). For example, according to the NINCDS-ADRDA-criteria, the diagnosis of a probable AD is possible without impairment of daily life activities, although it is necessary for the diagnosis according to the ICD 10. Moreover, a dementia syndrome was diagnosed only if the MMSE score was below 25. 
In 2004, the definition of mild cognitive impairment was improved by Winblad et al. [37,38]. MCI is the most widely used classification for individuals who have subjective memory or cognitive complaints, objective memory or cognitive impairments, and whose activities of daily living are generally normal.

As pointed out in the introduction, the first clinical sign of AD is impairment in episodic memory, more specifically a deficit in delayed free recall. There are several other neurological and cardiovascular diseases, which show cognitive decline, but these do not specifically affect episodic memory. In this study, we therefore decided to use a $\mathrm{z}$-score of $\leqslant-1.5$ for wordlist recall as a cut-off score to separate patients into groups of amnesic or non-amnesic MCIs. Moreover, all MCI patients had an MMSE score higher than 24. Classifying patients as amnesic and non-amnesic MCI was performed while being blind for the level of $\mathrm{A} \beta-{ }_{1-42}$ and total tau in CSF (see below).

\section{Determination of tau protein and $A \beta_{1-42}$ in $C S F$}

Lumbar punctures were performed between lumbar vertebral body 4 and 5 , by a trained neurologist, using a 22-gauge Sprotte spinal needle. Approximately $5 \mathrm{ml} \mathrm{CSF}$ was taken. CSF samples were free from any blood contamination. It was collected in polypropylene tubes and transported to an adjacent laboratory within 30 min. CSF samples were analyzed for cell count, total protein, lactate, glucose, IgG, IgA, IgM, Borrelioses antibodies, $\mathrm{A} \beta_{1-42}$ and total tau protein. Apart from the specimen used for the cell count, some CSF was briefly centrifuged at low speed ( $4000 \mathrm{rpm}$ for $7 \mathrm{~min}$ ) to pellet any cellular elements; these were stored at a temperature of $4^{\circ} \mathrm{C}$ (unfrozen) and analyzed within 7 days. CSF total tau was determined quantitatively using a commercial sandwich enzyme-linked immunosorbent assay (Innotest ${ }^{\circledR}$ hTAU-Ag, Innogenetics, Ghent, Belgium). $\operatorname{CSF} \mathrm{A} \beta_{1-42}$ was determined using a sandwich ELISA (Innotest ${ }^{\circledR} \beta$-amyloid ${ }_{1-42}$, Innogenetics, Ghent, Belgium). All tests for $\mathrm{A} \beta_{1-42}$ and total tau were performed at the Medizinisches Labor Bremen (Dr. A. Gerritzen) according to the recommendations of the manufacturer Innogenetics.

\section{Statistical evaluation}

Neuropsychological assessment was based on ageand education corrected z-scores (for the CERAD-NP) and on age-corrected scores for most of the other neuropsychological tests. In the statistical evaluation we used the parametric Pearson correlation and we used a $\mathrm{p}$-value of $p<0.01$ as criterion for significance for all correlational analyses (which were performed as twosided tests, as usual). We tested for Group differences in age, level of education, MMSE and BDI, using the non-parametric Kruskal-Wallis Test, because of deviations from the normal distribution. In the case of a significant Group effect, we used the Mann-Whitney U-Test for paired group comparisons. For the CSF markers, we used an analysis of variance and t-tests for analyzing group differences.

\section{RESULTS}

\section{Demographic data}

In this study, we recruited 36 patients with $\mathrm{AD}$ and 37 with MCI: Of the 36 patients with AD, 18 of them had mild dementia (MMSE 18-24), 15 had moderate dementia (MMSE 10-17), and 3 had a severe dementia (MMSE < 10). Of the 37 patients with MCI 25 patients showed an amnesic MCI and 12 a non-amnesic MCI. There were no significant differences in age and education between AD patients and amnesic MCIs patients, but significantly more patients in the MCI group were male compared to the AD patients. The non-amnesic MCI group did not differ from the amnesic MCI and the AD group in age, education, and gender distribution. See for demographic details Table 1.

Mean total tau concentration was $665 \mathrm{ng} / \mathrm{l}$ for the group of $\mathrm{AD}, 415 \mathrm{ng} / \mathrm{l}$ for the amnesic MCI group, and $285 \mathrm{ng} / \mathrm{l}$ for the non-amnesic MCI group. According to Weimer \& Fröhlich, the cut-off value for total tau in a group of patients below the age of 71 years is $450 \mathrm{ng} / 1$, which fits with our data [39].

$\mathrm{A} / \beta_{1-42}$ was $469 \mathrm{ng} / \mathrm{l}$ for AD patients, $661 \mathrm{ng} / \mathrm{l}$ for amnesic MCI patients, and $813 \mathrm{ng} / \mathrm{l}$ for non-amnesic MCIs. Clearly, both variables showed a wide range. According to Blennow, the level of $\mathrm{A} \beta_{1-42}$ in CSF is age independent and should be in $\mathrm{AD}$ patients about $50 \%$ of the value of healthy subjects [40]. This is almost the case in our study.

The two MCI groups did not show significant differences, but the AD group had a significantly higher tau value than the amnesic MCI group (t: $2.347, p=$ $0.022)$ and the non-amnesic MCI group (t: -2.748 , $p=0.009$ ). Moreover, $\mathrm{A} \beta_{1-42}$ was significantly decreased in this group compared to the MCI group ( $\mathrm{t}$ : $-2.675, p=0.01)$ and to the non-amnesic MCI group (t: $4.134, p=0.000)$. 
Table 2

Neuropsychological test results of the CERAD-ND test battery and additional tasks

\begin{tabular}{lrrrrrr}
\hline & \multicolumn{2}{c}{ AD } & \multicolumn{2}{c}{ amn-MCI } & \multicolumn{2}{c}{ Non amn-MCI } \\
\cline { 2 - 6 } & Mean & SD & Mean & SD & Mean & SD \\
\hline Word lexicon decision task & 23.7 & 8.3 & 27.1 & 5.5 & 24.5 & 7.1 \\
Phonological fluency & 15.4 & 7.8 & 21.3 & 9.3 & 19.7 & 11.0 \\
Digit span forward & 5.9 & 2.1 & 6.3 & 2.3 & 6.2 & 2.0 \\
Digit span backward & 3.5 & 1.6 & 5.8 & 4.9 & 4.6 & 1.6 \\
Cognitive speed (Zahlen- & 112.0 & 96.5 & 56.5 & 67.9 & 49.6 & 21.6 \\
Verbindungstest) & & & & & & \\
(seconds) & & & & & & \\
CERAD- NP* & & & & & & \\
MMSE* & -6.95 & 3.50 & -2.40 & 1.39 & -1.92 & 1.83 \\
Semantic fluency* & -2.22 & 1.08 & -1.57 & 0.64 & -1.24 & 1.09 \\
Boston naming* & -1.85 & 1.59 & -0.70 & 1.12 & 0.23 & 0.83 \\
Wordlist learning* & -3.96 & 1.27 & -2.29 & 0.88 & -1.15 & 0.80 \\
Wordlist delayed recall* & -3.10 & 0.98 & -2.10 & 0.86 & -0.71 & 0.85 \\
Wordlist intrusions* & -0.70 & 1.33 & -0.39 & 1.28 & 0.23 & 1.07 \\
Wordlist savings* & -2.19 & 1.36 & -1.47 & 1.20 & -0.15 & 0.93 \\
Wordlist discrimination* & -2.93 & 1.38 & -1.81 & 0.99 & 0.00 & 1.30 \\
Visuo-construction* & -2.00 & 1.30 & -0.93 & 2.04 & -1.21 & 1.43 \\
Visuo- construction recall* & -2.67 & 0.78 & -1.69 & 1.02 & -1.10 & 1.17 \\
Visuo- & -2.54 & 0.96 & -1.56 & 1.10 & -0.74 & 1.13 \\
savings* construction & & & & & & \\
\hline & & & & & & \\
\hline
\end{tabular}

*age- and education corrected z-scores (for the CERAD-NP).

\section{Neuropsychological assessment}

For the neuropsychological test results, we refer to Table 2. We found significant differences between the amnesic and non-amnesic MCI groups for the Boston naming test, word list learning, word list recall, word list savings, word list recognition, and constructional ability savings. We found significant differences between $\mathrm{AD}$ and MCI-groups for every task, as expected. Amnesic, but not non-amnesic MCIs, differed from AD patients on the BDI (t: $-2.226, p=0.03)$, but the average BDI score of 13.6 was in the range of mild depressive symptoms.

\section{CSF and neuropsychological investigation}

We found no correlation at all between neuropsychological test scores and CSF markers in the AD group. In the amnesic MCI group, the correlation between $\mathrm{A} \beta_{1-42}$ and word list learning $(r=0.583, p=0.002)$ was significant. Cognitive speed $(r=0.507, p=$ $0.011)$, visuo-spatial memory performance (savings) $(r=0.483, p=0.014)$, and the MMSE z-score $(r=$ $0.465, p=0.019)$ just failed to reach the significance criterion $(p<0.01)$. We found no significant correlation between Tau and neuropsychological test results in all three groups. See for detailed information Table 3.

The correlation plots for $\mathrm{A} \beta_{1-42}$ and wordlist learning illustrate the significant correlation for the amnesic
MCI group, but not for the other groups (Fig. 1AC). Although the correlation of cognitive speed and $\mathrm{A} \beta_{1-42}$ just failed to become significant in the amnesic MCI group, the correlation plot (Fig. 1D) suggests there might be an association between cognitive speed and $\mathrm{A} \beta_{1-42}$, but also that this association might be absent in patients with already rather low $\mathrm{A} \beta_{1-42}$ levels.

Combining both MCI groups into one group and looking for correlations between CSF markers and neuropsychological functioning revealed three significant results $(p<0.01)$ : wordlist learning and $\mathrm{A} \beta_{1-42}(r=$ $0.491, p=0.002)$, wordlist delayed recall and $\mathrm{A} \beta_{1-42}$ $(r=0.434, p=0.007)$ and cognitive speed and $\mathrm{A} \beta_{1-42}$ $(r=0.443, p=0.009)$.

\section{DISCUSSION}

We found a significant correlation between $\mathrm{A} \beta_{1-42}$ and memory performance in the amnesic MCI group. No clear correlation was observed between $\mathrm{A} \beta_{1-42}$ and other cognitive tasks, neither in the amnesic MCI group, nor in the non-amnesic MCI group. Finally, there were no significant correlations between any of the neuropsychological tests and $\mathrm{A} \beta_{1-42}$ (using ageand education corrected z-scores) in the $\mathrm{AD}$ group.

The strong correlation between $\mathrm{A} \beta_{1-42}$-concentration in the CSF and memory performance in amnesic MCI patients, but not in AD patients, indicates that 
Table 3

Correlation between $\mathrm{A} \beta_{1-42}$ and neuropsychological test results

\begin{tabular}{|c|c|c|c|c|c|c|}
\hline & \multicolumn{2}{|l|}{$\mathrm{AD}$} & \multicolumn{2}{|c|}{ amn-MCI } & \multicolumn{2}{|c|}{ n-amn-MCI } \\
\hline & correlation & $\mathrm{p}$ & correlation & $\mathrm{p}$ & correlation & $\mathrm{p}$ \\
\hline MMSE & $\mathrm{ns}$ & & $0.465^{*}$ & 0.019 & $\overline{\mathrm{ns}}$ & \\
\hline Word list learning & $\mathrm{ns}$ & & $0.583^{* *}$ & 0.002 & ns & \\
\hline Cognitive speed (Zahlenverbindungstest) & $\mathrm{ns}$ & & $-0.507^{*}$ & 0.011 & $n s$ & \\
\hline Visuo-construction recall & $\mathrm{ns}$ & & $0.422^{*}$ & 0.036 & $-0.635^{*}$ & 0.027 \\
\hline Visuo-construction savings & ns & & $0.483^{*}$ & 0.014 & $-0.609^{*}$ & 0.036 \\
\hline
\end{tabular}

Only test scores with at least one significant correlation are shown. Significant scores beyond the defined $p<0.01$ are shown in italics and only for more complete information of the reader. ${ }^{* *} p<0.01,{ }^{*} p<0.05$.
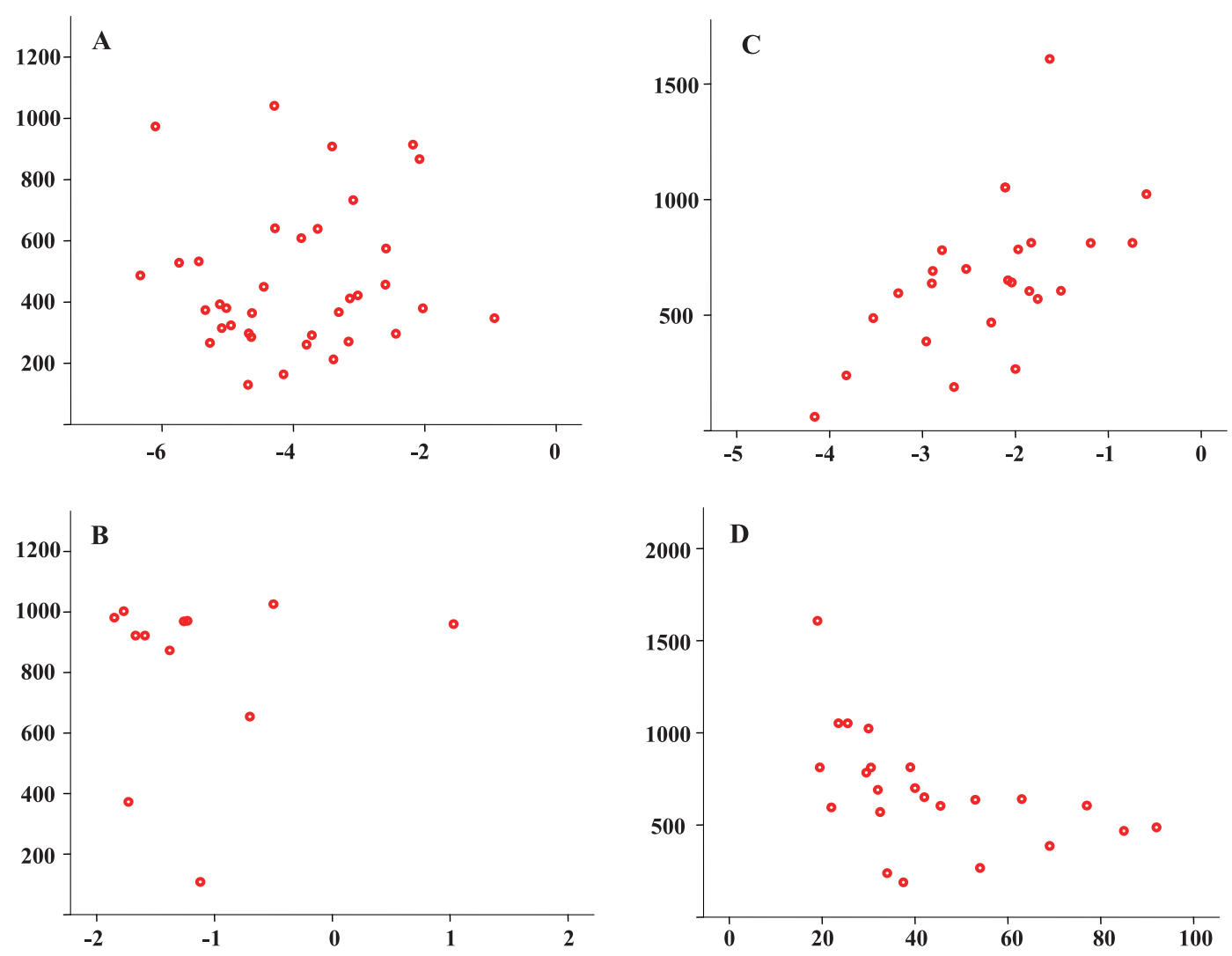

Fig. 1. A) Patients with $\mathrm{AD}$, correlation between $\mathrm{A} \beta_{1-42}$ and wordlist learning (z-Scores); B) Patients with non-amnesic MCI, correlation between $\mathrm{A} \beta_{1-42}$ and wordlist learning (z-Scores); C) Patients with amnesic MCI, correlation between $\mathrm{A} \beta_{1-42}$ and wordlist learning (z-Scores); D) Patients with amnesic MCI, correlation between $\mathrm{A} \beta_{1-42}$ and cognitive speed (in seconds). Y-axis: $\mathrm{A} \beta_{1-42}$ in CSF (ng/l), X-axis: cognitive performance.

specifically the decrease of $\mathrm{A} \beta_{1-42}$ in the CSF may reflect disease progression in AD during the early clinical stage of the disease, i.e., the MCI stage. Although cognitive speed just failed to reach the significance criterion in the group of amnesic MCI, our data suggest such a correlation, at least for the beginnings of the decline of the $\mathrm{A} \beta_{1-42}$-concentration in the CSF. In the dementia syndrome stage (MMSE $<25$ ), the decrease of $\mathrm{A} \beta_{1-42}$ seems to have reached a plateau and subsequent functional disease progression is related to processes like cell death and increasing brain atrophy.

Our results correspond essentially with the model proposed by Ingelsson et al. and the hypothetical model of dynamic biomarkers of the AD pathological cascade of Jack et al. [5,6]. However, in contrast to these models, our findings indicate that $\mathrm{A} \beta$ accumulation, and subsequent concentration decline in CSF, seems to be not yet in a steady state during early disease stages, i.e., in MCI patients, but reaches a plateau level as the patients show a clear-cut dementia syndrome. In our 
view, this difference in the time relation between cognitive decline and CSF $\mathrm{A} / \beta_{1-42}$ level is nevertheless compatible with previous empirical studies. Ivanoiu \& Sindic [21] and Stomrud et al. [17] reported that a low level of $\mathrm{A} \beta$ predicts cognitive decline in MCI patients. Maccioni and coworkers [43] showed that $\mathrm{A} \beta_{1-42}$ level correlates with cognitive performance in MCI patients after dividing the patient group in different degrees of impairment. In a recent study of Forsberg et al. [44], which only involved memory testing and no other cognitive tests, a correlation was found between $\mathrm{A} \beta_{1-42}$ level and memory performance in the MCI patients, but not in the AD patients. Some studies failed to find significant results $[15,45]$, but they have used the MMSE, and we have argued that the MMSE is not sensitive enough for measuring early cognitive decline. It lacks a proper test for episodic memory impairment, which is the first and core sign of the beginning of AD. The neuropathological changes leading to $\mathrm{AD}$, therefore, can be shown only using a sensitive episodic memory tests as in the CERAD NP, (and, perhaps, having broad population and education norms. Therefore we used z-scores for the correlational analysis).

In a recent study, Stomrud et al. reported an association of low CSF A $\beta_{1-42}$ levels with impaired episodic memory and reduced cognitive speed for healthy older adults, features that are commonly observed in early stages of pathological aging [46]. This may be interpreted according to the models of Ingelsson et al. [5] and Jack et al. [6] as showing that $\mathrm{A} \beta_{1-42}$ accumulation precedes the first clinical signs of AD. However, our study replicates exactly the results of Stomrud et al. [46] for amnesic MCI patients, that is, a correlation between memory performance and cognitive speed with the $\mathrm{A} \beta_{1-42}$ level. This pattern of results suggests that the beginning of $\mathrm{A} \beta_{1-42}$ decline may start already in a preclinical stage, and still progresses during the MCI stage.

The distinction between amnesic and non-amnesic MCI is not yet generally accepted, although there is a consensus that memory disorders, especially of delayed recall, are the core feature of early AD [10-16]. We tried to reproduce our findings by combining both MCI groups into one group. Again, $\mathrm{A} \beta_{1-42}$ (but not tau) correlated with wordlist learning, but in this larger group also with wordlist delayed recall and with cognitive speed. Our results therefore hold for both, the more specific (amnesic MCI) and the more general use (MCI defined by any kind of cognitive impairment) of this diagnostic entity.

We did not find any significant correlation between the increase of tau in the CSF and neuropsychologi- cal test performance. The relationship between neuropathological changes and increase or decrease of biomarkers in the CSF is not clarified in detail, but the models of Ingelsson et al. and Jack et al. indicate that in the first stages, disease progress is reflected in a decrease of $\mathrm{A} \beta_{1-42}$, and in an advanced stage in an increase of tau protein. In general, individuals from our study population were in a relatively early clinical stage, and even in the AD group, most patients showed only a mild dementia. Possibly, a significant correlation between tau protein and neuropsychological scores can be proven only in later stages of the disease.

There may be yet another reason why we did not find a correlation between neuropsychological test performance and CSF tau protein, in contrast to previous studies [19-21]. The increase of tau in the CSF might be much slower than the decrease of $\mathrm{A} \beta_{1-42}$, continuing longer into later stages of the disease. Buchhave and colleagues published one of the few longitudinal studies on tau and $\mathrm{A} \beta_{1-42}$ in patients with $\mathrm{AD}, \mathrm{MCI}$ and healthy controls with a follow-up of four years [48]. They found that only the tau level increases in AD and that this increase is comparatively small $(16 \%)$. To demonstrate such a slow but steady increase of tau requires the inclusion of large numbers of patients, and this might very well explain the somewhat contradictory results on the association between tau level and cognitive decline in AD. A longitudinal study on memory performance and tau protein, using a large number of patients in different disease stages, would probably reveal such a correlation.

In the introduction, we suggested that $\mathrm{A} \beta_{1-42}$ might correlate specifically with memory performance, because this is the hallmark in early stages of AD. However, the widespread accumulation of $\mathrm{A} \beta_{1-42}$ containingplaques seems to be non-specifically distributed in the brain, and this distribution pattern does not seem to suggest a specific relation with memory performance. Two considerations seem to be relevant here: First, the correlation between cognitive speed and $\mathrm{A} \beta_{1-42}$ in the CSF just missed the defined level of significance for our group of amnesic MCIs. Together with the findings of Molinuevo et al. [49] and Stomrud et al. [46], this indicates that the $\mathrm{A} \beta_{1-42}$ level in CSF also correlates with visual search, a typical temporo-parietal function. Therefore, cognitive decline in preclinical AD also involves cognitive functions other than episodic memory. Second, there are also some indications, that $\mathrm{A} \beta_{1-42}$ accumulation may disturb hippocampal neuronal connections and memory performance specifically. Mormino and collaborators demonstrated a re- 
lationship between $\mathrm{A} \beta$ deposition (as measured with PIB imaging), hippocampal atrophy and episodic memory. They concluded that a decline in episodic memory in older individuals may be caused by $\mathrm{A} \beta_{1-42^{-}}$ induced hippocampus atrophy, with $\mathrm{A} \beta_{1-42}$ deposition as the primary event in this cascade [50]. In line with this explanation, longitudinal hippocampal volume losses in individuals with MCI appear to be closely associated with a decrease in CSF $\mathrm{A} \beta_{1-42}$ levels and increasing hyperphosphorylated tau [51]. Moreover, our results correspond with a recent study from Petrie, in which correlations are shown between hypometabolism in FDG-PET: Lower $\mathrm{A} \beta$ is associated with hypometabolism, but only in the medial temporal lobe, and higher tau concentration is associated with hypometabolism in several brain regions [52].

There are some limitations of our study, which have to be mentioned. First, an unrecognized variability of the CSF marker might limit interpretation of the CSF marker, because we did not investigate reproducibility of the Innogenetic assays, which we used in this study. It has been reported that the variability of measurement is somewhat larger for $\mathrm{A} \beta_{1-42}$ than for tau. However, innogenetic assay should be less prone to measurement errors than other assays [47]. Moreover, in general, an increased variability should reduce the correlation coefficient, and should not produce spurious significant results.

Second, we classified MCI patients as amnesic MCIs on the basis of their scores on delayed recall and we subsequently calculated the correlation between neuropsychological test results and $\mathrm{A} \beta_{1-42}$ or tau. To prevent this potential confounding, it would have been better to classify patients in a way independent from neuropsychological test scores, but that is hardly possible. It should also be noted that classification of MCI patients was performed independently from the concentration of $\mathrm{A} \beta_{1-42}$ and tau, and delayed recall scores also were not used for classifying AD patients.

Third, our study used a cross-sectional design and therefore we do not know whether all of our amnesic MCI are early AD patients. The rate of progression from mild cognitive impairment to dementia varies among authors and depends on different criteria for classification. A three-year prospective study from Palmer et al., for example, indicates that approximately two-third of the multiple domain-MCI patients and half of the amnesic MCI patients progressed to AD [41, 42]. However, assuming that some of our amnesic MCI patients do not have AD pathology, the correlation between memory performance and $\mathrm{A} \beta_{1-42}$ might even by stronger than our results indicate.
In conclusion, we would like to argue that the decrease of $\mathrm{A} \beta_{1-42}$ in CSF mirrors disease progression during the early stages up into $\mathrm{AD}$, and it is therefore not restricted to the preclinical phase without any functional symptoms. $\mathrm{A} \beta_{1-42}$ shows clear correlation with memory performance and probably with cognitive speed and visual search. The decrease of $\mathrm{A} \beta_{1-42}$ seems to reach a plateau in the state of dementia and further functional disease progression is then related to neurodegeneration without further reduction of $\mathrm{A} \beta_{1-42}$ in the CSF. The increase of tau seems to be much slower and possibly extends over the entire period of the progression into AD. Therefore, the inclusion of many patients is required in order to evaluate the relationship between Tau and neuropsychological performance with good accuracy.

\section{ACKNOWLEDGMENTS}

The authors gratefully acknowledge the constructive comments from 3 anonymous reviewers to an earlier version of this paper.

Authors' disclosures available online (http://www.jalz.com/disclosures/view.php?id=564).

\section{REFERENCES}

[1] Hardy J, Duff K, Hardy KG, Perez-Tur J, Hutton M (1998) Genetic dissection of Alzheimer's disease and related dementias: amyloid and its relationship to tau. Nat Neurosci 1, 355-358.

[2] Hardy J, Selkoe DJ (2002) The amyloid hypothesis of Alzheimer's disease: progress and problems on the road to therapeutics. Science 297, 353-356.

[3] Näslund J, Haroutunian V, Mohs R, Davis P, Greengard P, Buxbaum JD (2000) Correlation between elevated levels of amyloid beta-peptide in the brain and cognitive decline. JAMA 283, 1571-1577.

[4] Crystal H, Dickson D, Fuld P, Masur D, Scott R, Mehler M, Masdeu J, Kawas C, Aronson M, Wolfson L (1988) Clinicopathologic studies in dementia: nondemented subjects with pathologically confirmed Alzheimer's disease. Neurology 38, 1682-1687.

[5] Ingelsson M, Fukumoto, H, Newell KL Growdon JH, HedleyWhyte ET, Frosch MP, Albert MS, Hyman BT, Irizarry MC (2004) Early A $\beta$ accumulation and progressive synaptic loss, gliosis, and tangle formation in AD brain. Neurology 62, 925931.

[6] Jack CR, Knopman DS, Jagust WJ, Leslie MS, Aisen PS, Weiner MW, Petersen RC, Trojanowski JQ (2010) Hypothetical model of dynamic biomarkes of the Alzheimer's pathological cascade. Lancet Neurol 9, 119-128.

[7] Lowndes G, Savaqge G (2007) Early detection of memory impairment in Alzheimer's disease: a neurocognitive perspective on assessment. Neuropsychol Rev 17, 193-202. 
[8] Mickes L, Wixted JT, Fennema-Notestine C, Galasko D, Bondi MW, Thal LJ, Salmon DP (2007) Progressive impairment on neuropsychological tasks in a longitudinal study of preclinical Alzheimer's disease. Neuropsychology 21, 696-705.

[9] Lambon Ralph MA, Patterson K, Graham N, Dawson K, Hodges JR (2003) Homogeneity and heterogeneity in mild cognitive impairment and Alzheimer's disease: a crosssectional and longitudinal study of 55 cases. Brain 126, 23502362 .

[10] Hutchinson AD, Mathias JL (2007) Neuropsychological deficits in frontotemporal dementia and Alzheimer's disease: A meta-analytic review. J Neurol Neurosurg Psychiatry 78, 917-928.

[11] Reed BR, Mungas DM, Kramer JH, Ellis W, Vinters HV, Zarow C, Jagust WJ, Chui HC (2007) Profiles of neuropsychological impairment in autopsy-defined Alzheimer's disease and cerebro-vascular disease. Brain 130, 731-739.

[12] Busse A, Bischkopf J, Riedel-Heller SG, Angermeyer MC (2003) Subclassifications for mild cognitive impairment. Psychol Med 33, 1029-1038.

[13] De Jager CA, Hogervorst E, Combrinck M, Budge MM (2003) Sensitivity and specificity of neuropsychological tests for mild cognitive impairment, vascular cognitive impairment and Alzheimer's disease. Psychol Med 33, 1039-1050.

[14] Mariani E, Monastero R, Mecocci P (2007) Mild cognitive impairment: a systematic review. J Alzheimers Dis 12, 23-35.

[15] Jacova J, Kertesz A, Blair M, Fisk JD, Feldman HH (2007) Neuropsychological testing and assessment for dementia. Alzheimers Dement 3, 299-317.

[16] Zakzanis KK, Andrikopoulos J, Young DA, Champbell Z, Sethian T (2003) Neuropsychological differentiation of lateonset schizophrenia and dementia of the Alzheimer's type. Appl Neuropsychol 10, 105-114.

[17] Stomrud E, Hansson O, Blennow K, Minthon L, Londos E (2007) Cerebrospinal fluid biomarkers predict decline in subjective cognitive function over 3 years in healthy elderly. $D e$ ment Geriatr Cogn Disord 24, 118-124.

[18] Mollenhauer B, Bibl M, Wiltfang J, Steinacker P, Ciesielcyk B, Neubert K, Trenkwalder C, Otto M (2006) Total tau protein, phosphorylated tau (181p) protein, beta-amyloid 1-42, and beta-amyloid 1-40 in cerebrospinal fluid of patients with dementia with Lewy bodies. Clin Chem Lab Med 44, 192-195.

[19] Wallin AK, Blennow K, Andreasen N, Minthon L (2006) CSF biomarkers for Alzheimer's disease: Levels of beta-amyloid, tau, phosphorylated tau relate to clinical symptoms and survival. Dement Geriatr Cogn Disord 21, 131-138.

[20] Sunderland T, Linker G, Mirza N, Putnam KT, Friedman DL, Kimmel LH, Bergeson J, Manetti GJ, Zimmermann M, Tang B, Bartko JJ, Cohen RM (2003) Decresed beta-amyloid 1-42 and increased tau levels in cerebrospinal fluid of patients with Alzheimer disease. JAMA 289, 2094-2103.

[21] Ivanoiu A, Sindic CJ (2005) Cerebrospinal fluid tau protein and amyloid beta42 in mild cognitive impairment: prediction of progression to Alzheimer's disease and correlation with the neuropsychological examination. Neurocase 11, 32-39.

[22] Hildebrandt H, Haldenwanger A, Ehling P (2009) False recognition correlates with amyloid- $\beta 1-42$ but not with total tau in cerebrospinal fluid of patients with dementia and mild cognitive impairment. J Alzheimers Dis 16, 157-165.

[23] Morris JC, Mohs RC, Rogers H, Fillenbaum G, Heyman A (1988) The consortium to establish a registry for Alzheimer's disease (CERAD). Clinical and neuropsychological assessment of Alzheimer's disease. Psychopharmacol Bull 24, 641652 .
[24] Morris JC, Heyman A, Mohs RC, Hughes JP, van Belle G, Fillenbaum G, Mellits ED, Clark C, and the CERAD investigators (1989) The consortium to establish a registry for Alzheimer's disease (CERAD). Part I. Clinical and neuropsychological assessment of Alzheimer's disease. Neurology 39, 1159-1165.

[25] Morris JC, Edland S, Clark C, Galasko D, Koss E, Mohs R, van Belle G, Fillenbaum G, Heyman A (1993) The consortium to establish a registry for Alzheimer's disease (CERAD). Part IV. Rates of cognitive change in the longitudinal assessment of probable Alzheimer's disease. Neurology 49, 2457-2465.

[26] Welsh KA, Butters N, Mohs RC, Beekly D, Edland S, Fillenbaum G, Heyman A (1994) The consortium to establish a registry for Alzheimer's disease (CERAD): A normative study of the neuropsychological battery. Neurology 44, 609-614.

[27] Barth S, Schönknecht P, Pantel J, Schröder J (1993) Mild Cognitive Impairment and Alzheimer's Disease: an investigation of the CERAD-NP Test battery. Fortschr Neurol Psychiat 73, $1-9$.

[28] Horn W (1983) Leistungsprüfsystem (LPS) Hans Huber Verlag, Bern.

[29] Lehrl S, Merz J, Burkard G, Fischer B (1991) MehrfachWortschatz-Intelligenztest (MWT-A). Perimed Fachbuchverlagsgesellschaft, Erlangen.

[30] Oswald WD, Fleischmann UM (1986) NürnbergerAltersinventar NAI, Textkasten und Kurzmanual. Universität Erlangen-Nürnberg, Erlangen.

[31] Wechsler D (1987) WMS-R - Wechsler Memory Scale - Revised. The Psychological Corporation, New York.

[32] Beck AT, Hautzinger M, Bailer M, Worall H, Keller F (1985) BDI - Beck-Depressionsinventar. Second edition. Hogrefe, Göttingen.

[33] World Health Organization (1992) ICD-10: international statistical classification of diseases and related health problemsbased on recommendations of the tenth revision conference, 1989 and adopted by the forty-third World Health Assembly, 10th edn. World Health Organization; Geneva.

[34] American Psychiatric Association (2000) Diagnostic and statistical manual of mental disorders $(I V-T R)$, 4th edn-text revised. Washington, DC.

[35] Dubois B, Feldman HH, Jacova C, DeKosky ST, BarbergerGateau P, Cummings J, Delacourte A, Galasko, D, Gauthier S, Jicha G, Meguro K, O’Brien J, Pasquir F, Robert P, Rossor M, Salloway S, Stern Y, Visser PJ, Scheltens P (2007) Research criteria for the diagnosis of Alzheimer's disease: revising the NINCDS-ADRDA criteria. Lancet Neurol 6, 734-746

[36] McKhann G, Drachman D, Folstein M, Katzman R, Price D, Stadlan EM (1984) Clinical diagnosis of Alzheimer's disease: report of the NINCDS-ADRDA Work Group under the auspices of Department of Health and Human Services Task Force on Alzheimer's Disease. Neurology 34, 939-944.

[37] Winblad B, Palmer K, Kivipelto M, Jelic V, Fratiglioni L, Wahlund, L-O, Nordberg A, Bäckman L, Albert M, Almkvist O, Arai H, Basun H, Blennow K, De Leon M, Decarli C, Erkinjuntti T, Giacobini E, Graff C, Hardy J, Jack C, Jorm A, Ritchie K, Van Duijn C, Visser P, Petersen RC (2004) Mild cognitive impairment-beyond controversies, towards a consensus: report of the International Working Group on Mild Cognitive Impairment. J Intern Med 256, 240-246.

[38] Petersen RC (2004) Mild cognitive impairment as a diagnostic entity. J Intern Med 256, 183-194.

[39] Weimer E \& Fröhlich L (2005) Labordiagnostik und Liquormarker bei Alzheimer Krankheit. In: Demenzen. Perspektiven in Praxis und Forschung, H. Förstl (ed.), Elsevier, pp. 59-85. 
[40] K. Blennow (2004) Cerebrospinal fluid protein biomarkers for Alzheimer's disease. NeuroRx 1, 213-225.

[41] Matthews FE, Stephan BCM, McKeith IG, Bond J, Brayne $\mathrm{C}$, and the Medical Research Council Cognitive Function and Ageing Study (2008) Two-year progression from mild cognitive impairment to dementia: to what extent do different definitions agree? J Am Geriatr Soc 56, 1424-1433.

[42] Palmer K, Bäckman L, Winblad B, Fratiglioni L (2008) Mild cognitive impairment in the general population: occurrence and progression to Alzheimer disease. Am J Geriatr Psychiatry 16, 603-611.

[43] Maccioni RB, Lavados M, Guillón M, Mujica C, Bosch R, Farías G, Fuentes P (2006) Anomalously phosphorylated tau and $\mathrm{A} \beta$ fragments in the CSF correlates with cognitive impairment in MCI subjects. Neurobiol Aging 27, 237-244.

[44] Forsberg A, Almkvist O, Engler H, Wall E, Lngström B, Nordberg A (2010) High PIB retention in Alzheimer's disease is an early event with complex relationship with CSF biomarkers and functional parameters. Curr Alz Res 7, 56-66.

[45] Tombaugh TN (2005) Test-retest reliable coefficients and 5year change scores for the MMSE and 3MS. Arch Clin Neuropsychol 20, 485-503.

[46] Stomrud E, Hansson O, Zetterberg H, Blennow K, Minthon L, Londos E (2010) Correlation of longitudinal cerebrospinal fluid biomarkers with cognitive decline in healthy older adults. Arch Neurol 67, 217-223.

[47] Verwey NA, van der Flier WM, Blennow K, Clark C, Sokolow S, De Deyn PP, Galasko D, Hampel H, Hartmann T, Kapaki E, Lannfeld L, Metha PD, Parnetti L, Petzold A, Pirttila T, Saleh L, Skinningsrud A, Swieten JC, Verbeek MM, Wiltfang
J Younkin S, Scheltens P, Blankenstein MA (2009) A worldwide multicentre comparison of assays for cerebrospinal fluid biomarkers in Alzheimer's disease. Ann Clin Biochem 56, 235-240.

[48] Buchhave P, Blennow K, Zetterberg H, Stomrud E, Londos E, Andreasen N, Minthon L, Hansson O (2009) PLoS One 4, e6294.

[49] Molinuevo JL, Gómez-Anson B, Monte GC, Bosch B, Sánchez-Valle R, Rami L (2010) Neuropsychological profile of prodromal Alzheimer's disease (Prd-AD) and their radiological correlates. Arch Gerontol Geriatr, in press.

[50] Mormino EC, Kluth JT, Madison CM, Rabinovici GD, Baker SL, Miller BL, Koeppe RA, Mathis CA, Weiner MW, Jagust WJ and the Alzheimer's Disease Neuroimaging Initiative (2008) Episodic memory loss is related to hippocampalmediated beta-amyloid deposition in elderly subjects. Brain 132, 1310-1323.

[51] de Leon MJ, DeSanti S, Zinkowski R, Mehta PD, Pratico D, Segal S, Rusinek H, Li J, Tsui W, Saint Louis LA, Clark CM, Tarshish C, Li Y, Lair L, Javier E, Rich K, Lesbre P, Mosconi L, Reisberg B, Sadowski M, DeBernadis JF, Kerkman DJ, Hampel H, Wahlund LO, Davies P (2006) Longitudinal CSF and MRI biomarkers improve the diagnosis of mild cognitive impairment. Neurobiol Aging 27, 394-401.

[52] Petrie EC, Cross DJ, Galasko D Schellenberg GD, Raskind MA, Peskind ER, Minoshima S (2009) Preclinical evidence of Alzheimer changes: convergent cerebrospinal fluid biomarker and fluorodeoxyglucose positron emission tomography findings. Arch Neurol 66, 632-637. 